\title{
Guided FNAC of nodular lesions in liver
}

\author{
Kanica Jha1, Anupama Gupta ${ }^{2, *}$, Meena Pangarkar ${ }^{3}$, D.T Kumbhalkar ${ }^{4}$, W.K Raut ${ }^{5}$ \\ ${ }^{\mathbf{1}}$ Assistant Professor, ${ }^{2}$ Associate Professor, ${ }^{3}$ Consultant, ${ }^{4}$ Professor, ${ }^{5}$ Professor and Head, ${ }^{\mathbf{1}, 2,4,5}$ Dept. of Pathology, ${ }^{3}$ Dept. of \\ Oncopathology ${ }^{\mathbf{1}, \mathbf{2 , 4}}$ Govt. Medical College, Nagpur, Maharashtra, ${ }^{3}$ National Cancer Institute, Nagpur, Maharashtra, India
}

*Corresponding Author:

Email: pama_gpta@rediffmail.com

\begin{abstract}
Introduction: A focal mass or a nodule in the liver has become easily accessible to the needle of a pathologist, courtesy the rising numbers of guided FNAC. Precise localisation of lesions helps in studying the cytological features in greater detail, of the area in question. A targeted needle aspiration achieves high rates of sensitivity and specificity with regard to the varied spectrum of the pathologies encountered in liver especially when correlated with serological tests. Thus present study was carried out with aim to assess the role of guided FNAC in the diagnosis of nodular lesions of liver and to study their cytomorphology. Materials and Methods: It is an observational, prospective study of 130 adequate aspirates from liver nodules done at tertiary care hospital over two year period. All patients presenting with nodular liver mass detected on imaging techniques were selected for FNAC under USG or CT guidance. Another pass was taken from the surrounding liver to ascertain the presence of parenchymal changes like fatty change, cirrhosis and dysplasia.

Results: Adequate aspirates from 130 cases were studied. Lesions were categorised into non neoplastic (11) and neoplastic which were further classified benign (1), primary malignancies (31HCC, 4 cholangiocarcinoma) metastasis (72) and undifferentiated malignancies (11) respectively on cytology.

Conclusion: Guided FNAC of the liver is a rapid simple and precise method of identifying the pathology in liver nodules. It can be a useful modality to triage the patients and decide further line of management.
\end{abstract}

Keyword: FNAC, Guided, Nodular lesions, Liver, Cirrhosis.

\section{Introduction}

Pathologies involving liver are varied and range from inflammatory to benign and malignant lesions. Many of these give rise to a nodule/s in the liver. Prolonged intake of alcohol above threshold values are known to cause crippling cirrhosis which in turn can act as a soil for development of hepatocellular carcinoma(HCC). ${ }^{1,2}$ Hepatitis B and Hepatitis C viruses are also associated with an increased risk of primary tumours of the liver. ${ }^{3}$

Malignant neoplasm of the liver are very aggressive and chemotherapy has limited value thus hepatectomy or liver transplant is the treatment of choice. ${ }^{4}$ Therefore early diagnosis and treatment is the need of the hour. Modalities like tru-cut biopsy has its own disadvantages like hospitalization, complications like bleeding due to deranged coagulation profile and processing time of biopsy. 5,6

Since the advent of guided Fine needle aspiration cytology (FNAC), the diagnostic accuracy of liver nodules, has improved significantly and reduced the incidence of bleeding. ${ }^{7}$ Guided FNAC, in conjunction with the clinical, imaging and serological data, provides quick, easy and fairly precise amount of information with great accuracy in liver nodules. ${ }^{8}$ Hence this study was carried out with an aim to assess the role of guided FNAC in the diagnosis of nodular lesions of liver and to study their cytomorphology.

\section{Materials and Methods}

It is an observational, prospective study of two years carried out at a tertiary care hospital. The aim of the study was to assess the role of guided FNAC in the diagnosis of nodular lesions of liver and to study their cytomorphology. All liver nodules larger than one centimetre $(\mathrm{cm})$ in either dimension on radiology (solid or cystic) were included in the study, irrespective of age and symptoms. Suspected hydatid cyst and haemangioma on imaging and inadequate aspirates were excluded from the study.

After informed consent and ethical clearance total 138 liver nodules were aspirated under ultra sound (USG) or Computerised tomography (CT) guidance using all aseptic precautions and intramuscular atropine to minimise blood loss using 23 gauge spinal needles. Coagulation profile was done in all patients prior to the procedure.

Dry and wet smears were prepared and stained with hematoxylin and eosin ( $\mathrm{H}$ and E), Papanicolaou (Pap) and May Grunwald Giemsa (MGG) stains. Second pass was taken in case of inadequate material. Another aspirate was taken from the surrounding liver (other than the area of the lesion) and smears were similarly prepared and stained. Post procedure it was ensured that there is no evidence of bleeding. Special stains were advised as and when needed. The reporting was done by a single observer to avoid inter-observer bias.

Data was entered and tabulated using the Microsoft Excel 2010 software and statistical analysis was done 
using the SPSS software. Kappa coefficient was used and sensitivity, specificity and diagnostic accuracy were calculated using Wilson score.

\section{Results}

Total 138 liver lesions were aspirated of which 130 were adequate, 8 were inadequate after re-aspiration and hence excluded from study. Of these 130 cases with adequate aspirates maximum patients were between 6170 years. The youngest patient was 4 months and the oldest was 75 years old with male predominance $(66.92 \%)$. Biochemical analysis revealed raised serum glutamic oxaloacetic transaminase (SGOT), serum glutamic pyruvic transaminase (SGPT), alkaline phosphatase (ALP) and bilirubin values in $23.84 \%$, $23.07 \%, 17.69 \%$ and $32.30 \%$ cases respectively. Hepatitis B surface antigen ( $\mathrm{HbsAg}$ ) was available in 98 cases, of which $25(25.51 \%)$ were positive. HbsAg was positive in $57.14 \%$ cases of hepatocellular carcinoma (HCC) and $12.00 \%$ cases of metastatic deposits.

Alpha feto protein (AFP) levels were estimated in 40 cases. Of these 20 each was of primary HCC and metastases. Raised AFP values above the cut off of 400 $\mathrm{ng} / \mathrm{ml}$ was detected in $80 \%$ cases of HCC and zero percent cases of metastases. ${ }^{9}$

Radiologically $29(22.30 \%)$ were of primary malignancy, 41/130 (31.53\%) of metastases, 12/130 $(9.23 \%)$ of benign/ non neoplastic and a broad categorisation into neoplastic was given in 48 (36.92\%) as specific categorisation was not possible. (Table 1) Single lesions predominated in HCC (70.96\%) and multiple lesions predominated in metastases $(63.88 \%)$. Cytologically (72/130) were of metastatic deposits followed by primary malignancies (31 HCC and 4 cholangiocarcinoma), 11 undifferentiated carcinoma, 11 non neoplastic (3 pyogenic abscess, 3 regenerative nodule, 3 dysplastic nodules, one fungal granuloma and one fibropolycystic disease) and one benign neoplasm (hepatic adenoma) respectively. (Table 2)
Surrounding liver was aspirated in 119 cases, of which HCC showed cirrhotic changes in 5 (16.92\%) dysplasia in $6(19.35 \%)$ and malignant hepatocytes in 7 cases $(22.58 \%)$ respectively whereas cases of metastasis showed cirrhotic change in 3 (4.16\%), dysplasia in $3(4.16 \%)$ and malignant cells in $5(6.94 \%)$ cases respectively as shown in Table 3.

Cytology in comparison to histopathology had sensitivity, specificity and positive predictive value (PPV) of $100 \%, 66.67 \%$ and $94.12 \%$ respectively. Cohen's kappa ratio was 0.7711 .

Cytology and radiology were correlated and the sensitivity, specificity and PPV were 94.12, 50\% and $94.12 \%$ respectively. The diagnostic accuracy was $89.47 \%$. Cohen's kappa ratio for radiology and cytology was 0.4412 .

Table 1: Radiological diagnosis of all cases

\begin{tabular}{|l|c|c|}
\hline \multicolumn{1}{|c|}{ USG/CT Diagnosis } & No of cases & Percent \\
\hline Metastatic liver disease & 41 & 31.53 \\
\hline Primary Malignancy & 29 & 22.30 \\
\hline Non neoplastic/ Benign & 12 & 9.23 \\
\hline Neoplastic & 48 & 36.92 \\
\hline Total & 130 & 100 \\
\hline
\end{tabular}

Table 2: Cytological diagnosis of liver nodules

\begin{tabular}{|l|c|c|}
\hline FNAC diagnosis & No of cases & Percent \\
\hline Non Neoplastic & 11 & 8.46 \\
\hline $\begin{array}{l}\text { Benign Neoplasm } \\
\text { (Hepatic adenoma) }\end{array}$ & 1 & 0.76 \\
\hline Malignant Neoplasm & $\begin{array}{c}31 \mathrm{HCC}+4 \\
\mathrm{CC}+72 \mathrm{Mets}\end{array}$ & 82.30 \\
\hline $\begin{array}{l}\text { Undifferentiated } \\
\text { carcinoma }\end{array}$ & 11 & 8.46 \\
\hline Total & 130 & 100 \\
\hline
\end{tabular}

HCC- Hepatocellular Carcinoma, CC-

Cholangiocarcinoma, Mets- Metastases

Table 3: Adjacent liver findings $(n=119)$

\begin{tabular}{|l|c|c|c|c|c|c|c|}
\hline $\begin{array}{l}\text { Cytological } \\
\text { diagnosis }\end{array}$ & $\begin{array}{c}\text { Normal } \\
\text { liver }\end{array}$ & $\begin{array}{c}\text { Reactive } \\
\text { hepatocytes }\end{array}$ & $\begin{array}{c}\text { Fatty } \\
\text { change }\end{array}$ & $\begin{array}{c}\text { Cirrhotic } \\
\text { change }\end{array}$ & $\begin{array}{c}\text { Dysplastic } \\
\text { change }\end{array}$ & $\begin{array}{c}\text { Malignant } \\
\text { hepatocytes }\end{array}$ & Total \\
\hline HCC & 7 & 5 & 0 & 5 & 6 & 7 & 30 \\
\hline Metastasis & 30 & 27 & 3 & 3 & 3 & 5 & 72 \\
\hline Undifferentiated & 2 & 5 & 1 & 0 & 0 & 3 & 11 \\
\hline Non- neoplastic & 6 & 0 & 0 & 0 & 0 & 0 & 6 \\
\hline
\end{tabular}

Table 4: Histopathology diagnosis of liver lesions in comparison to cytological diagnosis

\begin{tabular}{|l|c|c|}
\hline & $\begin{array}{c}\text { Histopathology } \\
\text { diagnosis }\end{array}$ & $\begin{array}{c}\text { Cytology } \\
\text { diagnosis }\end{array}$ \\
\hline Non neoplastic & 3 & 2 \\
\hline Neoplastic & 16 & 17 \\
\hline
\end{tabular}

\section{Discussion}

FNAC, a diagnostic modality often used for superficial lesions has spread its realm to deeper lesions due to superior radiological guidance which has increased precision and visualisation of these lesions. Radiological assisted diagnosis when combined with the needling of the lesion provides quick and reliable diagnosis. ${ }^{10}$ Endoscopic ultrasound guidance can access 
areas which are difficult by conventional USG, especially in targeting left lobe of the liver and gastrohepatic ligament lymph nodes. ${ }^{11}$ Thus cytology of the liver plays important role to distinguish benign from malignant lesions, especially in the Indian setup, as very few core biopsies are done due to lack of infrastructural support.

The major cause of nodular lesions in liver is primary or secondary malignancy. Liver receives the portal vein which drains all the abdominal visceral organs, and hence tumour cells get lodged in the liver. Many aetiologies are associated with primary liver malignancy like a background of cirrhosis and $\mathrm{HbsAg}$ positivity, other causes being dysplastic nodules, aflatoxins and androgenic steroids. ${ }^{12}$ Considering the increasing incidence of liver lesions and they being the cause of increasing morbidity, this study was carried out to assess the utility of cytology in diagnosing nodular liver lesions, understanding their variable patterns and also observe the status of the surrounding liver while correlating these findings with radiology.

The mean age of patients in our study was 52 years with male predominance. The reason being cellular aging and related oncogene activation, in addition decreased regenerative capacity makes hepatocyte more prone to damage by environmental and infectious agents responsible for carcinogenesis. ${ }^{13}$ Male preponderance in the liver malignancy is due to cirrhotic changes which could be alcohol related or unrelated. Alcoholic cirrhosis however is commoner in males. Cirrhosis itself is an independent risk factor for hepatocellular carcinoma. ${ }^{14}$

Hepatitis B and C viruses have found great etiological association with the development of primary liver malignancies in many studies. ${ }^{3}$ Patients with HbsAg infection are more likely to develop HCC in comparison to hepatitis C infection (HCV). ${ }^{15}$ Dual infection of hepatitis B (HBV) and HCV infection show higher morbidity in HCC, thus both the tests are important in identifying patients who need more aggressive course of therapy. ${ }^{16}$

HbsAg was done in 98/130, Out of 98 patients, 16 HCC $(57.14 \%)$ cases, $6(12 \%)$ metastatic and 3 cases of undifferentiated carcinoma were $\mathrm{HbsAg}$ positive. HCV positivity was not noted due to overall low prevalence. Kumar et al and Asim et al reported HbsAg positivity in $56.5 \%$ and $61 \%$ positivity in HCC patients. ${ }^{17,18}$ Hiotis reported $89(59.7 \%)$ and $38(25.5 \%) \mathrm{HBV}$ and HCV associated cancers respectively. ${ }^{15}$

Serum AFP value of $400 \mathrm{ng} / \mathrm{ml}$ was taken as the cut off according to European association for the study of the liver (EASL) guidelines. ${ }^{19}$ These levels provide a great deal of insight into the pathology of liver. Raised AFP levels were seen in 16/20 (80\%) patients of HCC whereas none of the metastatic cases showed raised levels. Kailapuri et al, Banerjee et al and Abbasi et al observed AFP positivity in $45.8 \%$ and $75 \%$ and $46.34 \%$ cases respectively. ${ }^{20-22}$ Though AFP suffers from lack of sensitivity and specificity it surely can be used as an adjunctive modality for diagnostic support. ${ }^{23}$ Recent studies point to the usage of combined markers namely des-gamma-carboxyprothrombin (DCP) and Lens culinaris agglutinin-reactive fraction of AFP (AFPL3). ${ }^{24,25}$ Serial estimations of AFP are always a better option in cases of doubt. ${ }^{26}$

According to an algorithm by Wee, radiological evaluation of cystic or solid component, size, location and the number of a liver mass is essential. Presence of cirrhosis is also of great help..$^{9}$ In our study $70.96 \%$ HCC presented as solitary mass and $63.88 \%$ metastasis presented as multiple nodules on radiology. Banerjee et al reported $20 \% \mathrm{HCC}$ as a single mass and $30 \%$ as multiple nodules, whereas metastasis presented as single mass in $20 \%$ and multiple nodules in $70 \% .{ }^{21}$ Ahuja et al, found 17/25 lesions of HCC were solitary space occupying lesions (SOL) and in metastatic cases 17 cases had multiple nodules. ${ }^{27}$

On radiology 12/130 (9.23\%), 41/130 (31.53\%), $29 / 130(22.30 \%)$ were classified as non neoplastic or benign, metastatic and primary malignancies respectively. 48/130 (36.92\%) lesions which were malignant on radiology but could not be classified into primary or metastatic were broadly categorised as neoplastic. Definitive cytological diagnosis into primary and metastasis was offered in $42 / 48$ of these cases, thus emphasizing on the importance of cytological evaluation. We had 17 nodules $<2 \mathrm{~cm}$ in either dimension on radiology, of these 4 were of $\mathrm{HCC}$, 11 of metastatic deposits, one each of cirrhotic nodule and dysplastic nodule respectively. $4 \mathrm{HCC}$ cases were of early HCC and radiological evaluation helped in there early assessment. Ohnishi evaluated 74 nodules with a median size of 11 millimetre $(\mathrm{mm})$, of which 7 were proven to be HCC on histology. 64 lesions were followed up and 18 of these increased in size and showed typical features of HCC..$^{28}$

HCC is the sixth most common cancer in the world. ${ }^{29}$ Though histopathological diagnosis is the gold standard; the liberty of biopsy is not always available. Hence cytology remains the only cheap and reliable technique with sensitivity rates approaching almost $100 \% .30$

Non neoplastic and benign lesions are comparatively less as compared to malignant lesions. We had one case of fungal granuloma in an immunocompromised patient and thorough search revealed hyphae, therefore it is of importance to rule out fungal infections especially in immune compromised individuals. ${ }^{31}$

Hepatic adenoma is a challenging diagnosis on cytology and is also a close differential of well differentiated HCC. We encountered an incidental mass in young female which on cytology revealed only benign looking normal hepatocytes in sheets and no evidence of dysplasia. On eliciting history patient was on oral contraceptive pills. Hence considering 
cytomorphology, radiology and clinical, a diagnosis of hepatic adenoma was offered. Careful search was done in this patient to rule out malignancy. Nasit et al also mentioned about the difficulty in diagnosing hepatic adenoma which can be mistaken as well differentiated HCC and focal nodular hyperplasia on cytology. ${ }^{32}$

A rare case of fibropolycystic disease was detected in a 23 year male. (Fig. 1A) This entity encompasses related lesions of the liver and biliary tract which are caused by abnormal embryologic development of the ductal plates. ${ }^{33}$ Smears showed fibrous tissue, mucoid background and normal hepatocytes. There was no exuberant inflammatory infiltrate. Radiology along with cytology proved helpful in arriving at the diagnosis.

Regenerative nodules often seen in alcoholic patients, present as multiple tiny nodules in liver. Typical features of cirrhosis like bile stasis, fatty change, nucleomegaly, binulceation can be seen with no evidence of malignancy. (Fig. 1B) Geramizadeh studied pure cirrhotic nodules and some HCC nodules which showed the typical cytological features of cirrhosis but absence of transgressing capillaries, mitosis, eccentric nuclei, and scant cytoplasm thus excluding HCC. ${ }^{29}$

Diagnosis of dysplasia on cytology is an interesting and rewarding exercise. Their association with HCC makes them essential to be diagnosed at an early stage. We observed smears from some patients showing hyperchromasia and atypia neither enough to be classified as hepatocellular carcinoma nor usual enough to be left. Cells here showed anisonucleosis with enlarged nuclei, hyperchromasia and normal nuclear cytoplasmic (N/ C) ratio in case of large cell dysplasia and increased N/C ratio in small cell dysplasia. (Fig. 1C and 1D) We had 3 such cases of which 02 were of large cell change and one was of small cell change and two of them were HbsAg positive. A study by Yasin et al was closest to ours amongst benign/ non neoplastic lesions. $^{34}$

We found HCC to be the most common primary malignancy (31/118) i.e. $26 \%$ of all malignant lesions. (Fig. 2 A and 2B) Nasit and Balani found HCC in $28 \%$ and $27 \%$ cases respectively, quite similar to us. ${ }^{32,35}$ Cholangiocarcinoma was the second common primary cancer in our study. It was very challenging to differentiate cholangiocarcinoma from metastatic adenocarcinoma. Cells were mostly cuboidal to columnar but typical clinical presentation of obstructive jaundice and characteristic desmoplastic stroma helped in arriving at diagnoses. (Fig. 2C, 2D) However it is recommended to offer this diagnosis in presence of strong radiological back up and ruling out a primary malignancy elsewhere. Soudah extensively studied liver FNAs and found more cases of cholangiocarcinoma $(10 \%)$ in comparison us which could be because of greater sample size in their study. ${ }^{36}$

We had 72 (71carcinoma and one lymphoma) cases of metastatic deposits in the liver, being the most common liver nodules in our study. Most common metastases were from adenocarcinoma of which most common primary site was gastrointestinal tract $(13.86 \%)$ followed by lung $(5.55 \%)$ and breast $(4.16 \%)$. We also encountered one case each of metastases of neuroblastoma and lymphoma. (Fig. 3A- D) Case of lymphoma was proved to be diffuse large $\mathrm{B}$ cell lymphoma on flow cytometry. Primary site of malignancy could not be ascertained in (65.27\%). Balani et al also reported most common metastases to be adenocarcinoma accounting for $55.76 \%$ cases. They also reported one case of lymphoma similar to our finding. ${ }^{35}$ Reddy et al, also stated gastrointestinal tract as the commonest site of metastasis followed by breast cancer. ${ }^{37}$ These findings of gastrointestinal tract being the most common site of primary are concordant with the findings published in standard text books. ${ }^{38}$

In our study, there were total 11 cases $(8.46 \%)$ which were classified into undifferentiated carcinoma as further classification was not possible. Hence these were given a differential diagnosis and were advised further investigations to find the primary tumour. Soudah et al had $2.8 \%$ lesions with unclear morphology and Goel et al had $17 \%$ cases of unclassified malignancies. ${ }^{36,39}$

The study of the surrounding liver is of great value in diagnosing a lesion in the liver. The most important association has been made with cirrhotic changes in the liver. We aspirated the surrounding liver in 119/130 cases. The rest of the cases couldn't be studied because the patients did not give consent for an aspirate from other site or the lesions involved the entire liver. Studies which have separately evaluated the surrounding liver are few. We had 31 cases of HCC but surrounding liver was aspirated in 30 as in one case the liver was completely involved by the lesion on radiology and no intervening area was visualized. Of these 30 cases we observed dysplasia in $6(20 \%)$, cirrhotic changes in $5(16 \%)$ and malignant hepatocytes in $7 / 30(23.33 \%)$ cases respectively. Presence of malignant cells in the surrounding liver in these 7 cases can be equated with multifocal lesion, satellite nodule or tumour infiltration.

Associated cirrhosis was detected on radiology in $19 \%$ cases. Ahuja et al reported the radiological association of cirrhosis in $40 \%$ cases of HCC, but cytological confirmation has not been done in their study. ${ }^{27}$ Kumar et al studied 213 HCC patients, out of these, $64 \%$ patients had histological evidence of cirrhosis. $^{2}$

Cytological evaluation of dysplasia is difficult and most studies focus on histological appearance. A cytohistological study by Chang et al on 64 nodular lesions showed hyperplastic nodules in 8 , large cell dysplasia in 26, well differentiated $\mathrm{HCC}$ in 9, moderately differentiated $\mathrm{HCC}$ in 6 , moderate to poorly differentiated $\mathrm{HCC}$ in 01 and poorly differentiated HCC in 01on histology, whereas large cell change was noted 
in $7(10 \%)$ cases on cytology and small cell change was cytologically and histologically detected in $47(73.43 \%)$ and $37(57.81 \%)$ lesions, respectively. The percentages of dysplasia in their study were much more maybe because of the high prevalence of the disease. ${ }^{40}$

Geramizadeh divided 140 liver nodules into two groups (100 were pure cirrhotic and 40 were of HCC). Cirrhotic cases without HCC showed small cell dysplasia in none of the cases but large cell dysplasia was present in $33 \%$ of the cases. Small cell dysplasia was also commonly identified in cirrhotic background of HCC cases. $^{29}$

We also found associated dysplasia in 3 cases of metastatic deposits which amount to $4.16 \%$ which is much lower in comparison to primaries and thus this could be a chance association. Metastatic deposits showed predominantly normal and reactive hepatocytes in the surrounding liver $(79.16 \%)$. Thus dysplasia was more common in surrounding liver of HCC than metastatic deposits.

Histopathology was also done in 19 cases in our study, but the number of biopsies received was very low in our centre. The reason for this is the strong reliance on FNAC because it is a quick, easy and affordable for the patient. Histopathology and cytological concordance was seen in 18 cases. (Table 4) The discordant case was cytologically diagnosed as deposits of adenocarcinoma whereas when the biopsy was evaluated there was no evidence of malignancy. This discrepancy was because the site of the lesion could not be targeted on biopsy. It was a small lesion of size $1.8 \times 2 \mathrm{~cm}$ in segment 5 of right lobe and cytology smears showed adequate cellularity with convincing malignant cells. The serum AFP was also low (3.72 $\mathrm{ng} / \mathrm{ml}$ ), and hence was supportive to our cytological diagnosis. A repeat biopsy was advised but the patient was lost to follow up. In a study by Apple baum et al data was obtained from 208 patients on whom both cytology and histology was performed and they found 25 cases had discordance. 7 out of these 25 cases were diagnosed only cytologically and 4/7 showed only normal liver cells and few malignant cells not sufficient enough to be called a carcinoma. ${ }^{41}$ Thus missing the lesion on biopsy is often a possibility, which can be minimised by cytology because of the ease of taking multiple passes.

The sensitivity and specificity of FNAC when compared to biopsy which is considered the gold standard is also very encouraging. Various studies have done combined cytological and histological study to come to this conclusion.

Statistical evaluation was done by Wilson score on three parameters namely radiology, cytology and histopathology. We evaluated 19 cases, in which we had the data of all three investigations. When comparing radiology with histopathology, we obtained a sensitivity and specificity of $93.75 \%$ and $33.3 \%$ respectively.
Similarly on comparing cytology with radiology the Cohens kappa was 0.4412 . A study by Khanna et al mentioned discordance rate of $4.7 \%$ between radiology and cytology and correlation in $92 \%$ cases. $^{42}$

On comparing cytology with histology using Wilson score, we found $100 \%$ sensitivity, $66.6 \%$ specificity, $94.12 \%$ positive predictive value and diagnostic accuracy of $94.74 \%$. These findings are similar to the study by Balani et al. ${ }^{35}$ Specificity was lower in our study probably due to less number of histopathological correlations as compared to other studies. Though the specificity in our study suffered, a positive predictive value of $94.12 \%$ was obtained. A study by Wang et al reported sensitivity of $91.5 \%$ and specificity of $100 \% .^{43}$

Thus it would be right to say from our study that cytological evaluation is particularly very helpful to pick up malignant liver lesions.

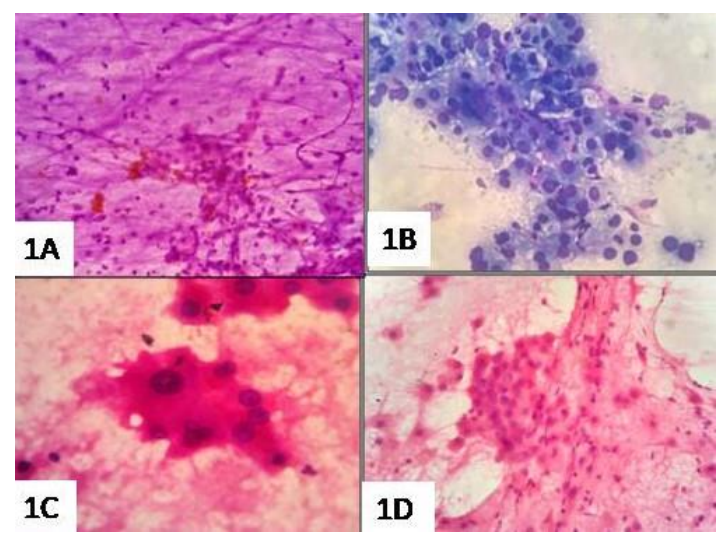

Fig. 1: 1A: (H \& E 10X) Smears of fibropolycystic disease showing mucoid background, scattered inflammatory cells, normal hepatocytes and fibrous tissue; 1B: (MGG 40X) Cirrhotic nodule smears showing fatty change in hepatocytes; 1C: (H \& E 40X) Smears from large cell dysplasia showing sudden anisonucleosis, hyperchromasia but maintained N/C ratio; 1D: (H \& E 40X) Smears of small cell dysplasia showing increased proliferation of small hyperchromatic cells having scanty cytoplasm and increased $\mathrm{N} / \mathrm{C}$ ratio 


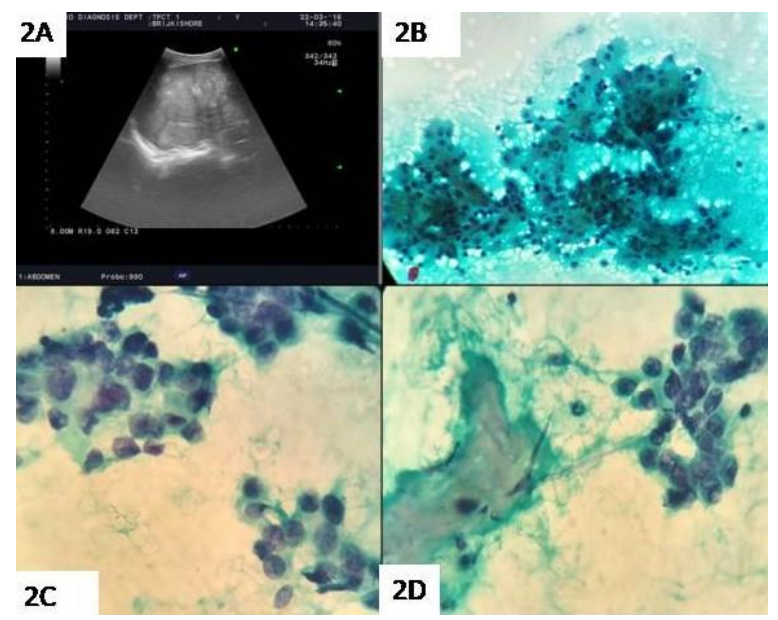

Fig. 2: 2A: USG showing single heterogeneous lesion in right lobe of liver; 2B: (Pap 40X) Smears from HCC showing transgressing capillaries in between malignant hepatocytes; 2C: (Pap 100X) Smears from cholangiocarcinoma showing cells in acini, round nucleus and scanty cytoplasm; 2D: (Pap 100X) Smears showing desmoplastic stroma of cholangiocarcinoma

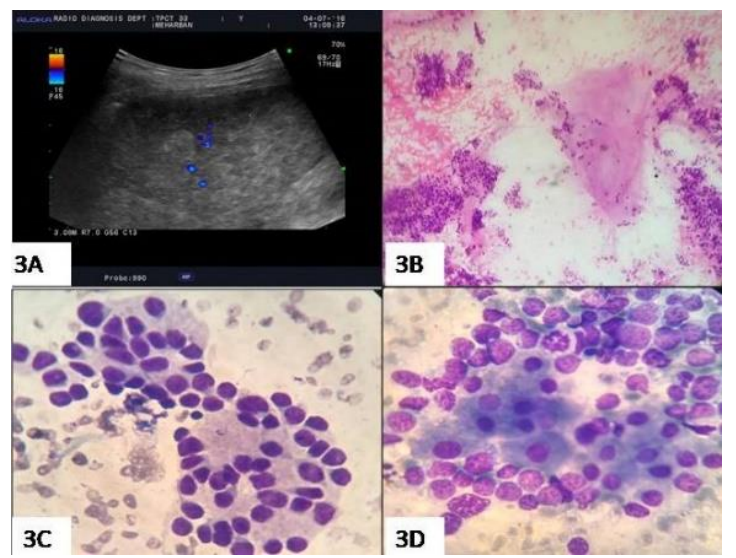

Fig. 3: 3A: USG showing multiple well defined hypoechoic areas in liver; 3B: (H \& E 10X) Smears showing deposits of adenocarcinoma colon along with mucin; 3C: (MGG 100X) Metastases of neuroblastoma showing small cells with neuropil like material; 3D: (MGG 100X) Metastases of lymphoma showing immature lymphoid cells along with normal hepatocytes

\section{Conclusion}

Guided FNAC is a rapid, safe and effective modality for precise localisation and diagnosis of nodular lesions of liver. It is of prime importance in deep seated lesions in critically ill patients due to less turnaround time more so in setups where biopsy is not readily available. Adjunctive tests like immunohistochemistry on cell block can be done in doubtful cases to increase the accuracy.
Aspirating the surrounding liver also gives a comprehensive insight into the altered milieu of the liver and diagnosing the lesion in view of the same reduces chances of error.

\section{Conflict of Interest: None}

\section{References}

1. Mokdad AA, Lopez AD, Shahraz S. Liver cirrhosis mortality in 187 countries between 1980 and 2010: a systematic analysis. BMC Med 2014;12:145.

2. Kumar M, Kumar R, Hissar SS, Saraswat MK, Sharma $\mathrm{BC}$, Sakhuja P, et al. Risk factors analysis for hepatocellular carcinoma in patients with and without cirrhosis: A case-control study of 213 hepatocellular carcinoma patients from India. $J$ Gastroentrol Hepatol 2007;22:1104-11.

3. De Oliveria Andrade LJ, D'Oliveira A, Melo RC, De Souza EC, Costa Silva CA, Paraná R. et al. Association between hepatitis $\mathrm{C}$ and hepatocellular carcinoma. J Glob Infect Dis 2009;1(1):33-37.

4. Romano O, Truant S, Sergent-Baudson G, Comet B, Pruvot FR, Hebbar M. et al. Docetaxel therapy for advanced hepatocellular carcinoma developed in healthy liver: Report of three cases. J Chemother 2008; 20:51820.

5. Tovikkai C, Charman SC, Praseedom RK, Gimson AE, Van Der Meulen J. Time-varying impact of comorbidities on mortality after liver transplantation: a national cohort study using linked clinical and administrative data. $B M J$ Open 2015; 5(5):e006971.

6. Van Beek D, Funaki B. Hemorrhage as a Complication of Percutaneous Liver Biopsy. Semin Intervent Radiol 2013;30(4):413-16.

7. Ji X-L. Fine-needle aspiration cytology of liver diseases. World J Gastroenterol 1999;5(2):95-7.

8. Das C, Mukhopadhyay M, Sengupta M, Saha AK, Mukhopadhyay B. Impact of image guided fine needle aspiration cytology in diagnosis of pediatric hepatic mass and cytohistologic concordance. J Indian Assoc Pediatr Sur 2014;19(2):90-5.

9. Wee A. Fine needle aspiration biopsy of the liver: Algorithmic approach and current issues in the diagnosis of hepatocellular carcinoma. Cytojournal. 2005; 2:7.

10. Barbhuiya M, Bhunia S, Kakkar M, Shrivastava B, Tiwari PK, Gupta S. et al. Fine needle aspiration cytology of lesions of liver and gallbladder: An analysis of 400 consecutive aspirations. J Cytol 2014; 31(1):20-24. doi:10.4103/0970-9371.130634.

11. Parekh PJ, Majithia R, Diehl DL, Baron TH. Endoscopic ultrasound-guided liver biopsy. Endosc Ultrasound. 2015;4(2):85-91. doi:10.4103/2303-9027.156711.

12. Assy N, Nasser G, Djibre A, Beniashvili Z, Elias S, Zidan J, et al. Characteristics of common solid liver lesions and recommendations for diagnostic workup. World J Gastroenterol 2009;15(26):3217-27. doi:10.3748/wjg.15.3217.

13. Tajiri K, Shimizu Y. Liver physiology and liver diseases in the elderly. World J Gastroenterol 2013;19(46):845967.

14. Ramakrishna G, Rastogi A, Trehanpati N, Sen B, Khosla R, Sarin SK, et al. From Cirrhosis to Hepatocellular Carcinoma: New Molecular Insights on Inflammation and Cellular Senescence. Liver Cancer 2013;2(3-4):367-83.

15. Hiotis S, Rahbari N, Villanueva G, Klegar E, Luan W, Wang Q, et al. Hepatitis B vs. Hepatitis C Infection on 
Viral Hepatitis-Associated Hepatocellular Carcinoma. BMC Gastroenterol 2012:12(64).

16. Benvegnu L, Fattovich G, Noventa F, Tremolada F, Chemello L, Cecchetto A, et al. Concurrent hepatitis B and $\mathrm{C}$ virus infection and risk of hepatocellular carcinoma in cirrhosis. A prospective study. Cancer 1994;74:244248.

17. Kumar R, Kumar M, Saraswat B, Sharma C, Sakhuja P, Sarin S. K, et al. Characteristics of hepatocellular carcinoma in India: a retrospective analysis of 191 cases. QJM: An Int J Med 2008;101(6):479-85.

18. Asim M, Sarma MP, Kar P. Etiological and molecular profile of hepatocellular cancer from India. Int. J. Cancer 2013;133:437-445.

19. Bruix J, Sherman M, Llovet JM, Beaugrand M, Lencioni R, Burroughs AK, et al. European Association for the Study of the Liver. Clinical management of hepatocellular carcinoma. Conclusions of the Barcelona2000 EASL conference. J Hepatol 2001;35:421-30

20. Kailapuri G. Murugavel, Mathews S, Jayanthi V, Shankar ME, Hari R, et al. Alpha-fetoprotein as a tumor marker in hepatocellular carcinoma: investigations in south Indian subjects with hepatotropic virus and aflatoxin etiologies. Int J Infect Dis 2008;12(6):71-6.

21. Banerjee A, Singh Laishram R, Meina Sigh A, Kulachandra Singh M, Chandra Sharma D. Cytomorphological Patterns of Nodular Lesions of liver. Iran J Pathol 2012;7(2):70-9

22. Abbasi A, Bhutto AR, Munir SM. Correlation of serum alpha feto protein and tumour size in hepatocellular carcinoma. J Pak Med Assoc 2012;62(1):33-6.

23. Daniele B, Bencivenga A, Megna AS, Tinessa V. Alphafetoprotein and ultrasonography screening for hepatocellular carcinoma. Gastroenterol. 2004;127(5):S108-12.

24. Sassa T, Kumada T, Nakano S, Uematsu T. Clinical utility of simultaneous measurement of serum highsensitivity des-gamma-carboxy prothrombin and Lens culinaris agglutinin A-reactive alpha-fetoprotein in patients with small hepatocellular carcinoma. Eur J Gastroenterol Hepatol 1999;11:1387-92.

25. Ikoma J, Kaito M, Ishihara T, Nakagawa N, Kamei A, Fujita N, et al. Early diagnosis of hepatocellular carcinoma using a sensitive assay for serum des-gammacarboxy prothrombin: a prospective study. Hepatogastroenterol 2002;49:235-38.

26. Arrieta O, Cacho B, Morales-Espinosa D, RuelasVillavicencio A, Flores-Estrada D, Hernández-Pedro N, et al. The progressive elevation of alpha fetoprotein for the diagnosis of hepatocellular carcinoma in patients with liver cirrhosis. BMC Cancer 2007;7:28.

27. Ahuja A, Gupta N, Srinivasan R, Klra N, Chawla Y, Rajwanshi A et al. Differentiation of hepatocellular carcinoma from metastatic carcinoma of the liver-clinical and cytological features. J Cytol 2007; 24:125-29.

28. Ohnishi H, Sakaguchi K, Nouso K. Outcome of small liver nodules detected by computed tomographic angiography in patients with hepatocellular carcinoma. Hepatol Int 2010;4(3):562-68.

29. Geramizadeh B, Asadi N, Tabei SZ. Cytologic Comparison between Malignant and Regenerative Nodules in the Background of Cirrhosis. Hepatitis Monthly 2012;12(7):448-452.

30. Soyuer I, Ekinci C, Kaya M, Genc Y, Bahar K. Diagnosis of hepatocellular carcinoma by fine needle aspiration cytology. Cellular features. Acta Cytol 2003;47(4):581-9.
31. Lipsett PA, Huang CJ, Lillemoe KD. Cameron JL, Pitt HA. Fungal hepatic abscesses: characterisation and management. J Gastrointest Surg 1997;1(1):78-84.

32. Nasit JG, Patel V, Parikh B, Shah M, Davara K. Fineneedle aspiration cytology and biopsy in hepatic masses: A minimally invasive diagnostic approach. Clin Cancer Investig J 2013;2:132-42.

33. Brancatelli G, Federle PM, Vilgrain V, Vullierme MP, Marin D, Lagalla R. et al. Fibro polycystic Liver Disease: $\mathrm{CT}$ and MR Imaging Findings. Radiographics 2005;25(3):659-70.

34. Yasin S, Bashir N, Samoon N. Role of image guided fine needle aspiration cytology in diagnosis of hepatic lesions - study at a tertiary care of Kashmir valley. Asian Pac J Health Sci 2017;4(2):198-205.

35. Balani S, Malik R, Malik R, Kapoor N. Cytomorphological variables of hepatic malignancies in fine needle aspiration smears with special reference to grading of hepatocellular carcinoma. J Cytol 2013;30(2):116-20.

36. Soudah B, Schirakowski A, Gebel M, Potthoff A, Braubach P, Schlue J et al. "Overview and evaluation of the value of fine needle aspiration cytology in determining the histogenesis of liver nodules: 14 years of experience at Hannover Medical School". Oncol Rep 2015;33(1):81-7.

37. Reddy CV, Goud YGB, Poornima R, Deshmane V, Madhusudhana BA, Gayathridevi M et al. Role of FNAC in Hepatic lesions: Risk of track metastases. South Asian J Cancer 2015;4(1):35-7.

38. Zaman M. Koss's Diagnostic cytology and its histopathologic basis. $5^{\text {th }}$ ed: Lippincott Williams and Wilkins; 2006.

39. Goel S, Hemrajani D, Sharma M. Ultrasound guided fine needle aspiration cytology (FNAC) in diagnosis of space occupying lesions (SOL) of liver. J Evol Med dent Sci 2014;3:7480-86.

40. Chang O, Yang Y, Masuzawa A, Fukushima N, Teramura $\mathrm{K}$, Hayashi $\mathrm{Y}$, et al. The cytological characteristics of small cell change of dysplasia in small hepatic nodules. Oncol Rep 2010;23(5):1229-32.

41. Appelbaum L, Kane R, Kruskal J, Romero J, Sosna J. Focal hepatic lesions: US-guided biopsy- lessons from review of cytologic and pathologic examination results. Radiol 2009;250(2):453-58.

42. Khanna M, Kaur K, Sharma M, Khanna A, Manjari M, Garg S, et al. Cytological- Raiological correlation of image guided FNAC of hepatic mass lesions: our experience in tertiary care centre. Ann Pathol Lab Med 2016;3(6):582-87.

43. Wang P, Meng ZQ, Chen Z, Lin JH, Ping B, Wang LF et al. Diagnostic value and complications of fine needle aspiration for primary liver cancer and its influence on the treatment outcome - a study based on 3011 patients in China. Eur J Surg Oncol 2008;34(5):541-46.

How to cite the article: Jha K, Gupta A, Pangarkar M, Kumbhalkar D.T, Raut W.K. Guided FNAC of nodular lesions in liver. Arch Cytol Histopathol Res 2018;3(4):166-172. 